\title{
DETERMINAÇÃO DE ISOTERMAS DE SORÇÃO DE UMIDADE PARA GRÃOS DE SOJA
}

\author{
C. D. dos SANTOS $^{1}$, H. B. MENEGOLLA ${ }^{1}$, A. H. ENGLERT ${ }^{2}$ e A. S. CASSINI ${ }^{1}$ \\ ${ }^{1}$ Universidade Federal do Rio Grande do Sul, Departamento de Engenharia Química (DEQUI). \\ ${ }^{2}$ Universidade Federal do Rio Grande do Sul, Instituto de Química, Departamento de Físico-Química \\ (DFQ). \\ E-mail para contato: claudiadestro@hotmail.com
}

\begin{abstract}
RESUMO - As isotermas de sorção são curvas que relacionam a umidade de um alimento com a sua atividade de água. O objetivo desse trabalho foi obter experimentalmente isotermas de sorção de grãos de soja nas temperaturas de 10,25 e $40^{\circ} \mathrm{C}$. Diversos modelos matemáticos selecionados foram testados para constatar qual melhor se ajusta aos dados experimentais. O método gravimétrico foi utilizado para a elaboração das isotermas e a relação de Clausius-Clapeyron foi usada para determinar o calor de sorção. Através dos experimentos foi possível determinar a umidade de equilíbrio dos grãos de soja para cada umidade relativa (atividade de água). As curvas de sorção de umidade obtidas foram do tipo II e o modelo matemático que melhor se ajustou foi o modelo de GAB. Adicionalmente, o calor total de sorção diminuiu com o aumento do teor de umidade de equilíbrio dos grãos.
\end{abstract}

\section{INTRODUÇÃO}

A soja é um alimento de grande importância para o consumo humano, bem como para a economia brasileira. A elevada proporção de proteínase aprópria composição dos grãos de soja tornam os mesmos uma ótima alternativa para uma alimentação saudável (Irigoyen e Giner, 2011).

O cultivo deste grão para a alimentação humana já era conhecido pelos chineses há milênios, entretanto, a inclusão deste alimento na dieta ocidental tornou-se comum apenas nas últimas décadas (MAPA, 2014). Com a inclusão desta fonte proteica na mesa brasileira, surgiu a necessidade de um maior conhecimento das suas funções nutricionais e benefícios para a saúde, além das características específicas dos grãos e as limitações produtivas do mesmo.

Um fator de grande influência nos grãos de soja, bem como nos alimentos em geral, é o seu teor de água; porém, a quantidade de água presente em um alimento não pode ser considerada uma medida do potencial de deterioração do mesmo. Logo, introduz-se um parâmetro que possibilita determinara estabilidade dos alimentos, o qual consiste na atividade de água $\left(a_{w}\right)$. Este indica a intensidade das forças que unem os componentes não aquosos do alimento com a água, e, por consequência, a água ainda disponível para ocorrência de reações químicas e bioquímicas (AlMuhtaseb et al., 2002; Nguyen et al., 2004). 
As isotermas de sorção de umidade são curvas que relacionam a umidade de um alimento com a sua atividade de água. Estas podem ser obtidas através de experimentos que relacionam a umidade relativa (constante) da atmosfera em que um alimento está submetido, uma vez alcançado o equilíbrio a uma temperatura constante, e o teor de umidade resultante no mesmo, sendo este conhecido como método estático gravimétrico (Al-Muhtaseb et al., 2002). Na Tabela 1 são apresentadas as umidades relativas de equilíbrio ( $100 \times a_{w}$ ), em cada temperatura, de soluções salinas frequentemente utilizadas na determinação das isotermas de sorção de umidade pelo método estático gravimétrico.

Tabela 1 -Atividade de água de soluções salinas saturadas.

\begin{tabular}{|l|l|l|l|}
\hline \multicolumn{1}{|c|}{ Composto } & $\mathbf{1 0}^{\circ} \mathbf{C}$ & $\mathbf{2 5}^{\circ} \mathbf{C}$ & $\mathbf{4 0}^{\circ} \mathbf{C}$ \\
\hline Hidróxido de potássio & 0,123 & 0,082 & 0,063 \\
\hline Acetato de potássio & 0,235 & 0,225 & 0,210 \\
\hline Cloreto de magnésio & 0,335 & 0,328 & 0,317 \\
\hline Carbonato de potássio & 0,440 & 0,432 & 0,430 \\
\hline Nitrato de magnésio & 0,574 & 0,529 & 0,484 \\
\hline Nitrito de potássio & 0,675 & 0,645 & 0,615 \\
\hline Cloreto de sódio & 0,760 & 0,753 & 0,755 \\
\hline Cloreto de potássio & 0,870 & 0,843 & 0,820 \\
\hline Cloreto de bário & 0,914 & 0,904 & 0,893 \\
\hline Sulfato de cobre II & 0,978 & 0,971 & 0,962 \\
\hline
\end{tabular}

Fonte: Greenspan (1977); Cassini (2004).

A compreensão dos fenômenos de sorção da umidade dos alimentos permite que as condições de embalagem e armazenamento sejam especificadas corretamente, além de auxiliar na predição da vida de prateleira do produto, bem como as possíveis mudanças físico-químicas provenientes do processamento (Tunç e Duman, 2007; Farahnaky et al., 2009). A atividade de água está relacionada com vários mecanismos que podem deteriorar o alimento, como o crescimento microbiano, a oxidação lipídica, as reações enzimáticas e o escurecimento não enzimático, os quais podem ser retardados se o alimento estiverembalado/armazenado em uma atividade de água adequada à natureza do produto (Tunç e Duman, 2007).

As isotermas de sorção de umidade são tipicamente observadas em cinco formatos diferentes (Tipo I, II, III, IV e V); o tipo I é conhecido como Langmuir e o tipo II como sigmóide (Al-Muhtaseb et al., 2002). Isotermas de sorção de umidade, quando aplicadas a alimentos, geralmente possuem a forma sigmóide (Tipo II). Este tipo de isoterma não é encontrado em todos os alimentos, pois o tipo da isoterma de sorção depende da natureza da matriz alimentícia (Al-Muhtaseb et al., 2002). Além disto, o conhecimento do tipo da isoterma não é suficiente para predizer a curva em questão.

São encontrados na literatura vários modelos matemáticos que descrevem as curvas de isotermas de sorção de umidade. Na Tabela 2 são apresentados alguns modelos comumente aplicados a alimentos e que são utilizados neste estudo. 
Tabela 2 - Modelos matemáticos de isotermas de sorção comumente aplicados a alimentos.

\begin{tabular}{|c|c|c|l|}
\hline $\begin{array}{c}\text { Nome do } \\
\text { modelo }\end{array}$ & Modelo & Equação & \multicolumn{1}{|c|}{ Referências } \\
\hline GAB & $X_{e q}=\frac{X_{m} C K a_{w}}{\left(1-K a_{w}\right)\left(1-K a_{w}+C K a_{w}\right)}$ & (1) & Al-Muhtaseb et al. (2002) \\
\hline Oswin & $X_{e q}=A\left(\frac{a_{w}}{1-a_{w}}\right)^{B}$ & $(2)$ & Oswin (1946) \\
\hline Halsey & $a_{w}=\exp \left(\frac{-A}{X_{e q}^{B}}\right)$ & (3) & Halsey (1948) \\
\hline Henderson & $X_{e q}=\left[\frac{\ln \left(1-a_{w}\right)}{1-a_{w}}\right]^{\frac{1}{B}}$ & (4) & Al-Muhtaseb et al. (2002) \\
\hline D'arcy Watt & $X_{e q}=\frac{K_{1} K_{2} a_{w}}{1+K_{1} a_{w}}+K_{5} a_{w}+\frac{K_{3} K_{4} a_{w}}{1-K_{3} a_{w}}$ & (5) & $\begin{array}{l}\text { Saravacos } \text { et al. } \\
\text { (1986) }\end{array}$ \\
\hline Peleg & $X_{e q}=K_{1} a_{w}^{n_{1}}+K_{2} a_{w}^{n_{2}}$ & (6) & Peleg (1993) \\
\hline
\end{tabular}

em que: $X_{e q}=$ umidade no equilíbrio; $a_{w}=$ atividade de água; $X_{\mathrm{m}}=$ umidade correspondente à monocamada; $K, A, B, C, K_{1}, K_{2}, K_{3}, K_{4}, K_{5}, n_{1}, n_{2}$ são constantes (parâmetros dos modelos).

O calor de sorção $\left(Q_{S}\right)$ é definido como o calor total de sorção $\left(Q_{T S}\right)$ no alimento menos o calor de vaporização da água, a uma dada temperatura. O calor de sorção é uma medida da energia liberada na sorção, e o calor de dessorção, a necessidade de energia para quebrar as forças intermoleculares entre as moléculas de água e as moléculas do sorvente. Assim, o calor de sorção é considerado como um indicativo das forças atrativas intermoleculares entre os componentes nãoaquosos e as moléculas de água (Al-Muhtaseb et al., 2002). O calor de sorção pode ser obtido através da Equação 7, a qual origina-se da equação de Clausius-Clayperon aplicada a um sistema de água pura, considerando que o calor de vaporização da água pura e o excesso referente ao calor de sorção não mudam com a temperatura e o teor de umidade do sistema mantém-se constante (Al-Muhtaseb et al., 2002).

$$
Q_{S}=-R \frac{d\left(\ln a_{w}\right)}{d\left(\frac{1}{T}\right)}
$$

em que R é a constante universal dos gases $(8,314 \mathrm{~J} / \mathrm{mol} . \mathrm{K})$ e $\mathrm{T}$ a temperatura absoluta $(\mathrm{K})$.

O objetivo desse trabalho foi determinar experimentalmente as isotermas de sorção de umidade para grãos de soja nas temperaturas de 10,25 e $40^{\circ} \mathrm{C}$, assim como avaliar qual dos modelos matemáticos selecionados melhor se ajusta aos dados experimentais obtidos. Ainda, foi calculado, a partir das isotermas obtidas nas diferentes temperaturas, o calor total de sorção em função da 
umidade dos grãos de soja.

\section{MATERIAIS E MÉTODOS}

\subsection{Determinaçãodas isotermas de sorção de umidade}

Isotermas de sorção dos grãos de soja foram determinadas nas temperaturas de 10,25 e $40^{\circ} \mathrm{C}$, utilizando-se o método estático gravimétrico. Para tanto, foram preparadas soluções saturadas dos sais apresentados na Tabela 1, acondicionadas em frascos hermeticamente fechados e colocadas em uma câmara climática (Incubadora Tecnal ${ }^{\circledR}$, modelo BOD TE 381, para as temperaturas de 10 e $40^{\circ} \mathrm{C}$ e câmara climática fabricada por ColdLab ${ }^{\circledR}$, modelo CL 350, para a temperatura de $25^{\circ} \mathrm{C}$ ).

Três béqueres contendo $10 \pm 0,1 \mathrm{~g}$ de grãos de soja (cada) foram colocados dentro de cada pote hermético, acima das respectivas soluções saturadas. Juntamente com as amostras, foi colocado um frasco com 0,5g de timol cristalino em cada pote para evitar o crescimento de fungos nas amostras (Wolf et al., 1985). Considerou-se que o equilíbrio foi atingido quando a variação de massa entre as pesagens foi menor que 1\% (Ayranci e Duman, 2005). As amostras em equilíbrio foram retiradas e analisadas quanto ao teor de umidade, pelo método gravimétrico da AOAC (1990). Os dados obtidos de teor de umidade de equilíbrio em função da atividade de água (umidade relativa/ 100 de cada frasco hermético) possibilitaram a construção das isotermas de sorção.

\subsection{Ajuste dos modelos matemáticos e cálculo do calor total de sorção}

Para analisar a qualidade do ajuste dos modelos apresentados na Tabela 2 aos dados experimentais (via regressão não-linear, utilizando o software Statistica ${ }^{\circledR}$ ), foram utilizados o coeficiente de determinação $\left(R^{2}\right)$, o percentual de erro médio relativo $(E M R)$ e o valor de chiquadrado $\left(\chi^{2}\right)$.

O calor total de sorção foi determinado a partir do cálculo do calor de sorção, através da Equação 7, somado ao calor de vaporização da água $(45,036 \mathrm{~kJ} / \mathrm{mol})$. Os valores de atividade de água $\left(a_{w}\right)$ em cada teor de umidade de equilíbrio $\left(X_{e q}\right)$, nas isotermas de 10,25 e $40^{\circ} \mathrm{C}$, foram preditos pelo modelo de GAB.

\section{RESULTADOS E DISCUSSÕES}

\subsection{Isotermas de sorção de umidade}

Foram obtidas, neste estudo, três isotermas de sorção de umidade de grãos de soja e todas estão apresentadas (médias \pm desvios-padrão) na Figura 1, juntamente com as isotermas preditas pelo modelo matemático que apresentou melhor ajuste aos dados experimentais (modelo de GAB). 


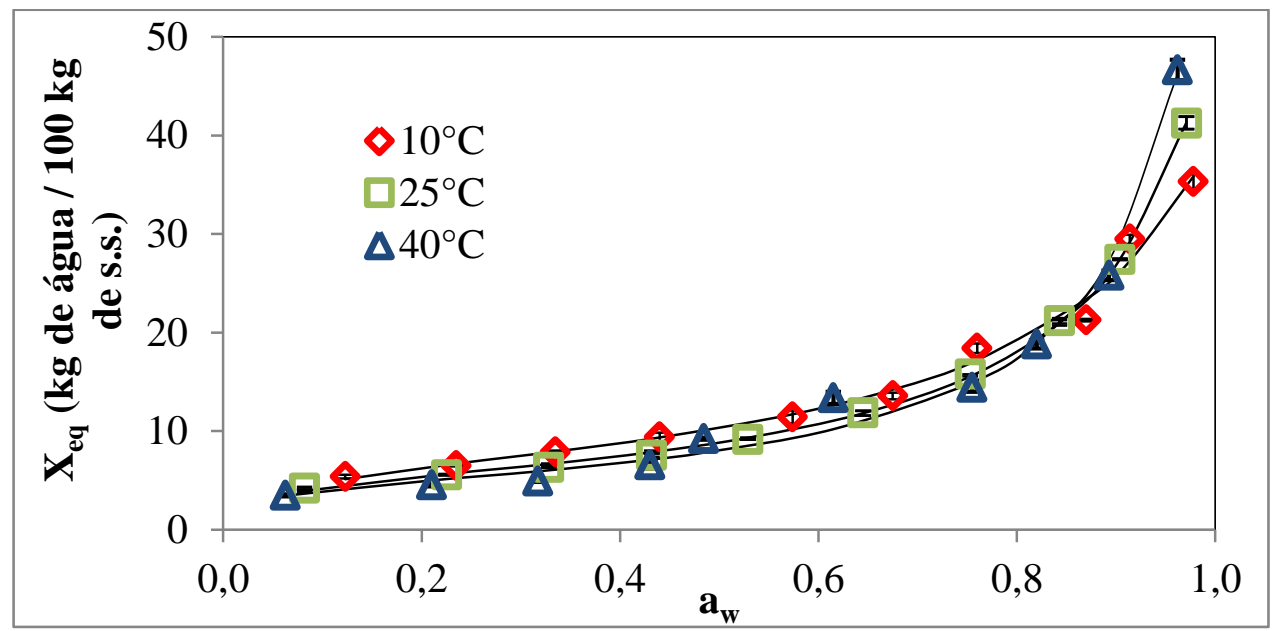

Figuras 1- Isotermas de sorção de umidade de grãos de soja obtidas nas temperaturas de 10, 25 e $40^{\circ} \mathrm{C}$ (símbolos), comparadas às correspondentes isotermas preditas pelo modelo de GAB (linhas).

Como podem ser observadas nesta figura, as isotermas obtidas para os grãos de soja são do tipo II (formato sigmóide), conforme obtido por diferentes autores para diversos produtos alimentícios, como produtos de cupuaçu (Medeiros et al., 2006), proteína isolada de algodão (Tunç e Duman, 2007) e figos (Farahnaky et al., 2009). Entretanto, as isotermas de grãos de soja verde obtidas por Yang et al. (2012) foram do tipo III.

\subsection{Ajuste aos modelos matemáticos e cálculo do calor de sorção}

Os parâmetros estimados no ajuste dos modelos apresentados aos dados experimentais e os fatores de avaliação dos ajustes $\left(R^{2}, E M R\right.$ e $\left.\chi^{2}\right)$ obtidos são apresentados na Tabela 3. Nesta tabela pode-se observar que todos os modelos testados apresentaram coeficientes de determinação superiores a 0,9542 . Logo, todos os modelos avaliados podem ser considerados adequados de acordo com esta avaliação. Contudo, os modelos de Oswin, Halsey, Henderson, D'arcy Watt e Peleg apresentaram erros médios relativos (EMR) maiores que 10\%, sendo assim considerados insatisfatórios para descrever os dados experimentais obtidos nas três isotermas para os grãos de soja.

O ajuste pelo modelo de GAB proporcionou coeficientes de determinação mais próximos da unidade, menores percentuais de erro médio relativo e menores valores de chi-quadrado na grande maioria das condições em todas as isotermas, quando comparado aos outros modelos. Desta forma, o modelo de GAB foi considerado o modelo que melhor representa as curvas de isoterma de sorção dos grãos de soja nas temperaturas estudadas.

O modelo de GAB (Guggenheim-Anderson-de Boer) é considerado uma extensão da equação de BET (Brunauer-Emmet-Teller) e considera as propriedades modificadas da água que é adsorvida na região de multicamadas (Heldman e Hartel, 2000). Este modelo é um dos mais utilizados na predição de isotermas de sorção de produtos alimentícios. Assim como neste trabalho, o modelo de 
GAB se mostrou o mais adequado no ajuste aos dados experimentais para outros alimentos: produtos de cacau e cupuaçu (Medeiros et al., 2006) e proteína texturizada de soja (Cassini et al., 2006).

Tabela 3 - Resultados dos ajustes dos modelos matemáticos aos dados experimentais obtidos de isotermas de sorção de umidade para grãos de soja nas temperaturas de 10,25 e $40^{\circ} \mathrm{C}$.

\begin{tabular}{|c|c|c|c|c|c|c|c|c|c|}
\hline Modelo & $\begin{array}{c}\text { Const. e } \\
\text { Par. }\end{array}$ & $10^{\circ} \mathrm{C}$ & $25^{\circ} \mathrm{C}$ & $40^{\circ} \mathrm{C}$ & Modelo & $\begin{array}{c}\text { Const. e } \\
\text { Par. }\end{array}$ & $10^{\circ} \mathrm{C}$ & $25^{\circ} \mathrm{C}$ & $40^{\circ} \mathrm{C}$ \\
\hline \multirow{6}{*}{ GAB } & $X_{m}$ & 6,32 & 5,02 & 4,36 & \multirow{5}{*}{ Halsey } & $A$ & 1276,02 & 158,26 & 29,92 \\
\hline & $C$ & 22,87 & 32,97 & 46,70 & & $B$ & 3,27 & 2,50 & 1,73 \\
\hline & $K$ & 0,84 & 0,91 & 0,94 & & $R^{2}$ & 0,9556 & 0,9821 & 0,9957 \\
\hline & $R^{2}$ & 0,9937 & 0,9998 & 0,9948 & & $\operatorname{EMR}(\%)$ & 15,41 & 13,83 & 12,57 \\
\hline & $\operatorname{EMR}(\%)$ & 4,16 & 2,22 & 8,99 & & $\chi^{2}$ & 8,83 & 3,56 & 1,69 \\
\hline & $\chi^{2}$ & 1,67 & 0,06 & 2,34 & \multirow{8}{*}{ D'arcy Watt } & $K_{l}$ & 0,91 & 0,78 & 1909190 \\
\hline \multirow{5}{*}{ Oswin } & $A$ & 11,46 & 9,82 & 8,74 & & $K_{2}$ & $-171,00$ & $-242,95$ & 1,98 \\
\hline & $B$ & 0,32 & 0,42 & 0,52 & & $K_{3}$ & 103,15 & 132,87 & 0,98 \\
\hline & $R^{2}$ & 0,9744 & 0,9945 & 0,9965 & & $K_{4}$ & 600,38 & 468,57 & 2,12 \\
\hline & $\operatorname{EMR}(\%)$ & 12,12 & 8,95 & 11,32 & & $K_{5}$ & $-11,32$ & $-9,99$ & 9,90 \\
\hline & $\chi^{2}$ & 5,87 & 1,75 & 1,39 & & $R^{2}$ & 0,9723 & 0,9542 & 0,9971 \\
\hline \multirow{7}{*}{ Peleg } & $K_{l}$ & 13,79 & 12,72 & 51,23 & & $\operatorname{EMR}(\%)$ & 14,89 & 23,83 & 9,44 \\
\hline & $n_{1}$ & 0,49 & 0,54 & 15,60 & & $\chi^{2}$ & 10,16 & 22,62 & 1,85 \\
\hline & $K_{2}$ & 24,92 & 35,51 & 19,37 & \multirow{5}{*}{ Henderson } & $k_{H}$ & 0,01 & 0,04 & 0,12 \\
\hline & $n_{2}$ & 5,94 & 7,68 & 1,02 & & $V$ & 1,72 & 1,33 & 0,87 \\
\hline & $R^{2}$ & 0,9937 & 0,9985 & 0,9958 & & $R^{2}$ & 0,989 & 0,993 & 0,983 \\
\hline & $\operatorname{EMR}(\%)$ & 4,36 & 5,88 & 14,92 & & $\operatorname{EMR}(\%)$ & 7,49 & 11,55 & 25,94 \\
\hline & $\chi^{2}$ & 1,94 & 0,63 & 2,19 & & $\chi^{2}$ & 1,28 & 2,85 & 2,27 \\
\hline
\end{tabular}

O calor total de sorção $\left(Q_{T S}\right)$ foi determinado com auxílio da Equação 7, utilizando-se valores de atividade de água $\left(a_{w}\right)$ preditos pelo modelo de GAB em cada teor de umidade de equilíbrio $\left(X_{e q}\right)$. A Figura 2 apresenta os resultados do calor total de sorção em função da umidade de equilíbrio dos grãos de soja.

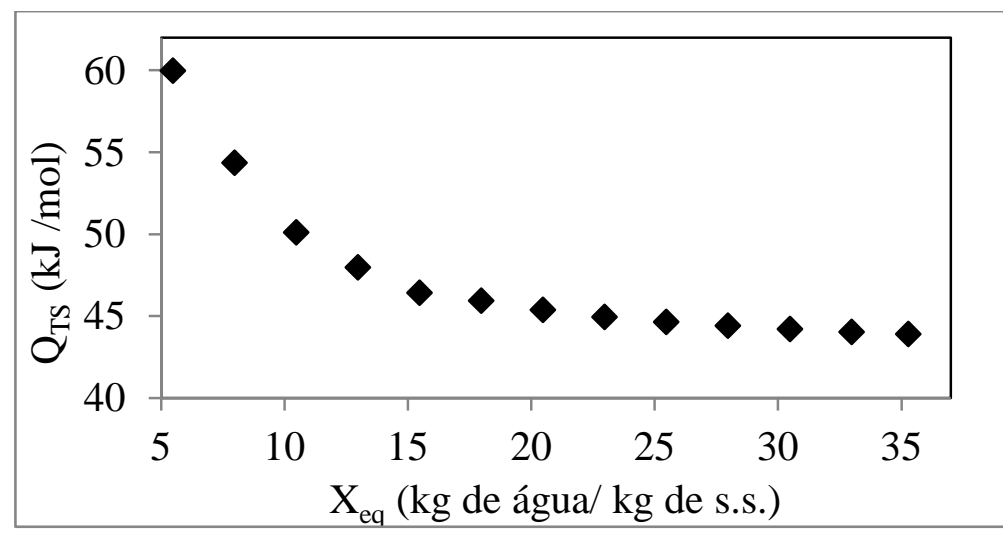

Figura 2 - Relação entre o calor total de sorção e a umidade de equilíbrio dos grãos de soja, obtida a partir das isotermas de sorção de umidade nas diferentes temperaturas. 
Como pode ser observado na Figura 2, o calor total de sorção $\left(Q_{T S}\right)$ diminui com o aumento do teor de umidade de equilíbrio dos grãos de soja. Isto ocorre, pois, quanto menor for o teor de umidade na amostra, maior é a quantidade de energia necessária para remover esta água (Al-Muhtaseb et al., 2002). Além disto, pode-se também observar nesta figura que o calor total de sorção atinge o calor de vaporização da água $(45,036 \mathrm{~kJ} / \mathrm{mol})$ em um teor de umidade dos grãos de soja de aproximadamente $22,5 \%$ (base seca).

\section{CONCLUSÃO}

Através das isotermas de sorção obtidas nas temperaturas de 10,25 e $40^{\circ} \mathrm{C}$, foi possível determinar a umidade de equilíbrio dos grãos de soja para cada umidade relativa (atividade de água) utilizada, em diferentes temperaturas. As curvas foram do tipo II e o modelo matemático que melhor se ajustou aos dados experimentais foi o modelo de GAB. Além disto, o calor total de sorção obtido diminuiu com o aumento do teor de umidadede equilíbrio dos grãos e atingiu o calor de vaporização da água $(45,036 \mathrm{~kJ} / \mathrm{mol}$ ) em um teor de umidade dos grãos de soja em torno de $22,5 \%$ (base seca).

\section{AGRADECIMENTOS}

Os autores agradecem à UFRGS por todo suporte fornecido, à CAPES (pela bolsa de pósdoutorado PNPD concedida ao Dr. Alexandre Hahn Englert entre 2012 e 2013), ao CNPq e à FAPERGS pelo apoio financeiro.

\section{REFERÊNCIAS}

AL-MUHTASEB, A. H.; McMinN, W. A. M.; MAGEE, T. R. A. Moisture sorption isotherm characteristics of food products: a review. Trans IChemE, v. 80, parte C, junho, 2002.

AOAC. Association of Official Analytical Chemists. Official Methods of analysis: 930,04. Moisture Content in Plants, v.1, p. 949, 1990.

AYRANCI, E.; DUMAN, O. Moisture sorption isotherms of cowpea (Vignaunguiculata L. Walp) and its protein isolate at 10, 20 and $30^{\circ} \mathrm{C}$. Journal of Food Engineering, v. 70, p. 83-91, 2005.

BRASIL. Ministério da Agricultura, Pecuária e Abastecimento. Embrapa Soja. Soja na Alimentação. 2014. Disponível em: http://www.cnpso.embrapa.br/soja_alimentacao/index.php Acesso em 07 de Abril de 2014.

CASSINI, A. S.; Análise das Características de Secagem da Proteína Texturizada de Soja. Dissertação de Mestrado, UFRGS, Porto Alegre, RS, Brasil, 2004.

CASSINI, A. S.; MARCZAK, L. D. F.; NOREÑA, C. P. Z. Water adsorption isotherms of texturized soy protein. Journal of Food Engineering, v. 77, p. 194-199, 2006.

FARAHNAKY, A.; ANSARI, S.; MAJZOOBI, M. Effect of glycerol on the moisture sorption isotherms of figs. Journal of Food Engineering, v. 93, p. 468-473, 2009. 
GREENSPAN, L. Humidity Fixed Points of Binary Saturated Aqueous Solutions. Journal of Research of the National Bureau of Standards-A.Physics and Chemistry, v. 81 A, n. 1, Jan-Fev, 1977.

HALSEY, G., Phisical Adsorption on Non-uniform Surfaces.Journal of Chemical Physics, v. 16, n. 10, p. 931-937, 1948.Citado por PARK, K. J.; VOHNIKOVA, Z.; BROD, F. P. R. Evaluation of Drying Parameters and Desorption Isotherms of Garden Mint Leaves.Journal of Food Engineering, v. 51, p. 193-199, 2002.

HELDMAN, D. R.; HARTEL, R. W. Principles of Food Processing.Chapman \& Hall, 2000.

IRIGOYEN, R. M. T., GINER, S. A. Volume and density of whole soybean products during hot-air thermal treatment in fluidized bed. Journal of Food Engineering, v. 102, p. 224-232, 2011.

MEDEIROS,M. L.; AYROSA, A. M. I. B.; PITOMBO, R. N. M.; LANNES, S. C. S. Sorption isotherms of cocoa and cupuassu products. Journal of Food Engineering, v. 73, p. 402-406, 2006.

NGUYEN, T. A., VERBOVEN, P., DAUDIN, J. D., NICOLAÏ, B. M. Measurement and modelling of water sorption isotherms of 'Conference' pear flesh tissue in the high humidity range. Postharvest Biology and Technology, v. 33, p. 229-241, 2004.

OSWIN, C. R.The kinetics of Package Life III: The Isotherm. Journal of Chem. Indust., 65, 419-421, 1946. In KAYMAK-ERTEKIN, F.; SULTANOGLU, M..Moisture Sorption Isotherm Characteristics of Peppers. Journal of Food Engineering, v. 47, p. 225-231, 2001.

PELEG, M. Assessment of a Semi Empirical Four Parameter General Model for Sigmoid Moisture Sorption Isotherms. Journal of Food Process Engineering, v.16, n.1, p. 21-37, 1993.

SARAVACOS, G. D.; TSIOURVAS, D. A.; TSAMI, E.Effect of Temperature on the Water Adsorption Isotherms of Sultana Raisins.Journal of Food Science, v. 51, p. 381-383, 1986.

TUNÇ, S., DUMAN, O. Thermodynamic properties and moisture adsorption isotherms of cottonseed protein isolate and different forms of cottonseed samples. JournalofFoodEngineering, v. 81, p. 133143, 2007.

WOLF, W.; SPIESS, W. E. L.; JUNG, G. Standardization of Isotherms Measurements (cost-project 90 and 90 bis). Properties of Water in Foods NATO ASI Series, v. 90, p. 661-679, 1985.

YANG, Z.; ZHU, E.; ZHU, Z. Moisture sorption isotherm and net isosteric heats of sorpition of green soybean. International Journal of Food Engineering, v. 8, artigo 15, 2012. 